\title{
FUNCTIONAL FOODS : BRIEF INFORMATION
}

\author{
M. M. Youssef \\ Food. Science \& Technology Dept., Fac. of Agric., \\ Alex. Univ., Alexandria, Egypt.
}

\begin{abstract}
Functional foods are those which may provide a health benefit beyond the nutritional nutrients they contain. Confusion exists about how to describe the newly evolving area of food and food technology due to presence of numerous interchangeable or related terms. Epidemiological, in vivo, in vitro and clinical trial data indicated that a plant based diet can reduce the risk of chronic disease, particularly cancer. Phytochemicals were found to play a key role in this respect. Meanwhile, there are functional foods from animal sources, fish contain omega-3 or n-3 fatty acids, fermented dairy products contain probiotics and beef contains conjugated linoleic acid, are all good examples for such foods. Obviously, there are no "good" or "bad" foods, but there are "good" or "bad" diets. Institutional and market innovation may be as important as technical innovation itself for leveraging the potential of functional foods.
\end{abstract}

Keywords : functional foods, phytochemicals, chemo preventive agents, designer foods, nutraceuticals, pharma foods.

\section{INTRODUCTION}

In recent years, functional foods have become part of the common vocabulary and, increasingly, part of the food menu (Kalaitzandonakes, 2000). According to Hasler (1998), the term functional foods was first introduced in Japan in the mid1980s and refers to processed foods containing ingredients that aid specific bodily functions in addition to being nutritious. Functional foods are defined as any modified food or food ingredient that may provide a health benefit beyond the traditional nutrients it contains (Milner, 1998).

Worldwide the functional foods business may be worth 50 billion Euro market with Europe alone being over 20 billion Euros. It is obvious that functional foods are big business and getting bigger. According to Milner (1998), ingestion of functional foods represents an effective strategy to maximize health and reduce risk of diseases, but they are not magic bullets that are functional under all circumstances. The positive message about foods, and the inclusion rather than exclusion of items from the diet may encourage consumers to be more accepting of this "functional foods" concept.

The point of interest is that there have been both notable successes and failures in market introductions of functional foods around the globe. According to Kalaitzandonakes (2000), this pattern will likely continue in the short run as consumers, producers and regulators move up the learning curve. In this transitional period, institutional and market innovation may be as important as technical innovation itself for leveraging the potential of functional foods.

\section{Characteristics of functional foods :}

A food can be regarded as "functional" if it is satisfactorily demonstrated to affect beneficially one or more target functions in the body, beyond adequate nutritional effects, in a way that is relevant to either an improved state of health and well-being and/or reduction of risk of diseases (Ashwell, 2002).

Functional foods must remain foods, and they must demonstrate their effects in amounts that can normally be expected to be consumed in the diet. They are not pills or capsules, but part of a normal food pattern. According to Ashwell (2002), the main points of the working definition for functional foods are :

a) Food nature of functional food : it is not a pill, a capsule or any form of dietary supplement. 
b) Demonstration of the effects to the satisfaction of the scientific community.

c) Beneficial effects on body functions, beyond an adequate nutritional effects, that are relevant to improved state of health and wellbeing and/or reduction of risk (not prevention) of disease.

d) Consumption as part of a normal food pattern.

Confusion exists about how to describe the "functional foods" as a newly evolving area of food and food technology. Such a confusion is due to presence of numerous interchangeable or related terms that have been suggested or published. These terms include : chemopreventive agents, designer food, functional food, nutraceutical, pharma food and phytochemical. Common to all of the aforementioned terms is the assumption that these foods or components found within them have a potential beneficial role in the prevention and treatment of disease. Other new terms, such as bioengineering, biotechnology and designer foods, relate to the technology available to develop phytochemical-rich food. According to ADA (1993), the aforementioned terms can be differentiated as follows :

\section{1- Chemopreventive agent :}

Nutritive or non-nutritive food component being scientifically investigated as a potential inhibitor of carcinogenesis for primary and secondary prevention.

\section{2- Designer food :}

Processed foods that are supplemented with food ingredients naturally rich in disease preventing substances. This may involve genetic engineering of food.

\section{3- Functional food :}

Any modified food or food ingredient that may provide a health benefit beyond the nutritional nutrients it contains.

\section{4- Nutraceutical :}

Any substance that may be considered a food or part of a food and provides medical or health benefits, including the prevention and treatment of disease.

\section{5- Pharma food :}

Food or nutrient that claims medical or health benefits, including the prevention and treatment of disease.

\section{6- Phytochemical :}

Substances found in edible fruits and vegetables that may be ingested by humans daily in gram quantities and that exhibit a potential for modulating human metabolism in manner favourable for cancer prevention.

\section{Functions of phytochemicals :}

Overwhelming evidence from epidemiological, in vivo, in vitro and clinical trial data indicated that a plant-based diet can reduce the risk of chronic diseases, particularly cancer. It is now clear that there are component in a plant-based diet other than traditional nutrients that can reduce cancer risk. More than a dozen classes of these biologically active plant chemicals now known as "phytochemicals" (Steinmetz and Potter, 1991, Block et al., 1992 Jenkins, 1993, ADA, 1995, Howard \& Kritchevsky, 1997, Ashwell, 2002).

The main components that may provide health benefits for human are given in Table (1) along with their main sources and potential benefits. As it can be seen, the most important phytochemicals in foods from plant sources include carotenoids, dietary fibers, flavonoids, glucosinolates, indoles, isothiocyanates, phenols, plant sterols, saponins, soy protein, phytoestrogens, sulfides' thiols and tannins.

\section{Functional foods from animal sources:}

Although the vast number of naturally occurring health-enhancing substances are of plant origin, there are a number of physiologically - active components in animal products that deserve attention for their potential role in optimal health: fish contain omega-3 (n-3) fatty acids; fermented dairy products contain probiotics and beef contains linoleic acid are good examples for functional foods from 
Table 1. The most important food components that may provide health benefits for human along with their main sources and potential benefits

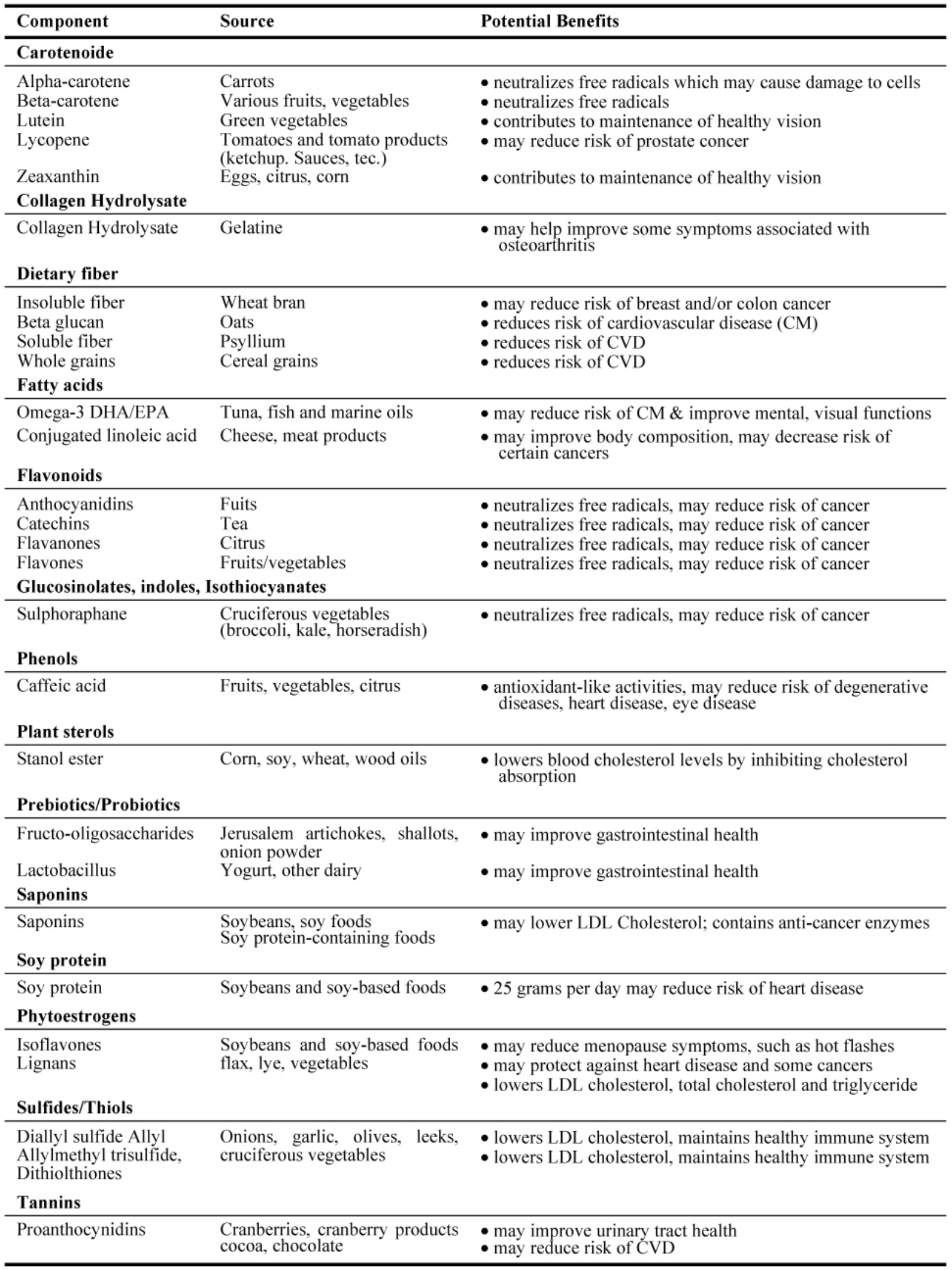

Ref. : Anonymous (2004). 
animal sources. Omega-3 (n-3) fatty acids may play an important role in decline the risk of CVD (Cardiovascular diseases) and derived primarily from fish oil (Hasler, 1998). Notwithstanding, probiotics present in the fermented dairy products are live microbial feed supplements which beneficially affect the host animal by improving its intestinal microbial balance (Fuller, 1994). Conjugated linoleic acid (CLA) largely present in beef is considered as an anticarcinogenic fatty acid. More recently, CLA has been investigated for its ability to change body composition, suggesting a role as a weight reduction agent. Mice fed CAL supplemented diets $(0.5 \%)$ exhibited $66 \%$ lower body fat and $14 \%$ increased lean body mass relative to controls (Park et al., 1997), possible by reducing fat deposition and increasing lipolysis in adipocytes.

\section{REFERENCES}

ADA 1993. Position of the American Dietetic Association : biotechnology and future of food. J. Am. Diet Assoc., 93: 189-192.

ADA 1995. Position of the American Dietetic Association : biotechnology and future of food. J. Am. Diet Assoc., 95: 493-496.

Anonymous 2004. Examples of functional components Esha Research Company (PDF file). http://download.esha.com./docs/functional.
Ashwell, A. 2002. Concepts of functional foods. The International Life Sciences Institute (ILSI) Europe Concise Monograph Series. pp.: 1-39 ILSI Europe, Belgium.

Block, B., Patterson, B. \& Subar, A. 1992. Fruits, vegetables and cancer prevention : A review of the epidemiological evidence. Nutr. Cancer, 18: 1-29.

Fuller, R. 1994. History and development of probiotics. In : Probiotics. (ed. R. Fuller), pp. : 1-8. Chapman \& Hall. N.Y.

Hasler, C.M. 1998. Functional foods : Their role in disease prevention and health promotion. Food Tehcnol., 52: 63-70.

Howard, B.V. \& Kritchevsky, D. 1997. Phytochemicals and cardiovascular disease. A statement for health care professionals from the American Heart Association. Circulation, 95: 2591-2593.

Jenkins, M.L.Y. 1993. Research issues in evaluating "functional foods". Food Technol., 47: 76-79.

Kalaitzandonakes, N. 2000. Functional foods : Technological, institutional and market innovation. Ag Bio Forum, 3: 1-2.

Milner, J.A. 1998. Do "functional foods" offer opportunities to optimize nutrition and health? Food Technol., 52: 24.

Park, Y., Albrigh, K.J., Liu, W., Storkson, J.M., Cook, M.E., \& Pariza, M.W. 1997. Effect of conjugated linoleic acid on body composition in mice. Lipids, 32: 853-858.

Steinmetz, K.A. \& Potter, J.A. 1991. Vegetables, fruits and cancer. II. Mechanisms. Cancer Causes Control, 2: 427-442.

\section{الأغلنيـــة|الوظيفيـةة : نبلذة مختصرة

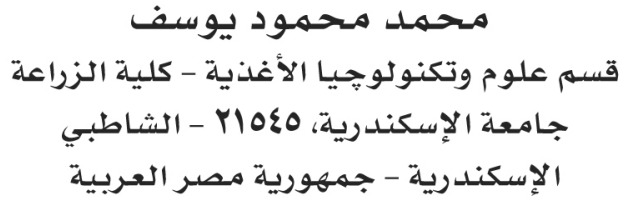

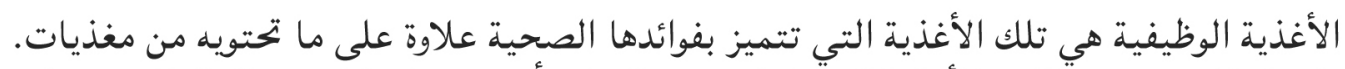

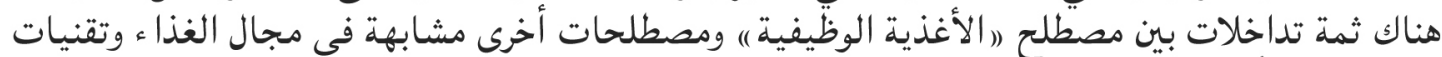

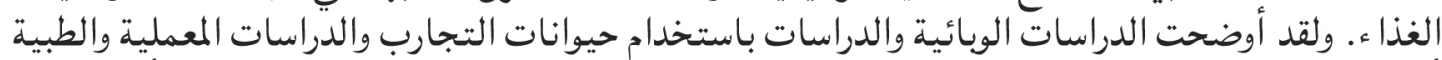

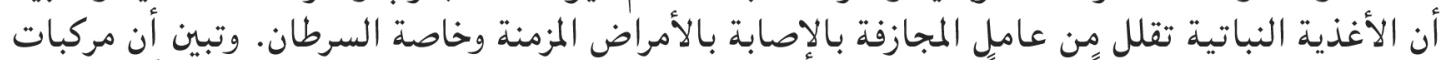

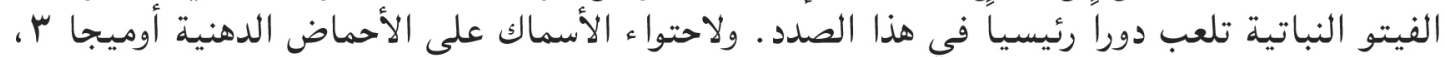

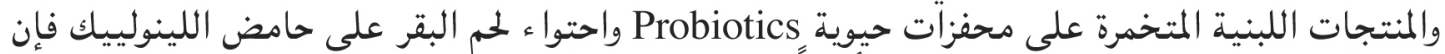

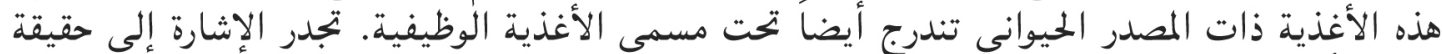

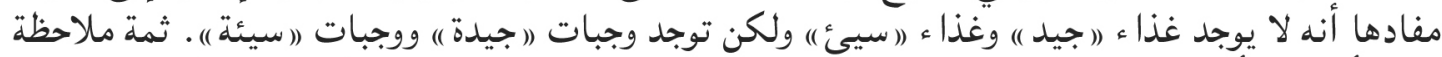

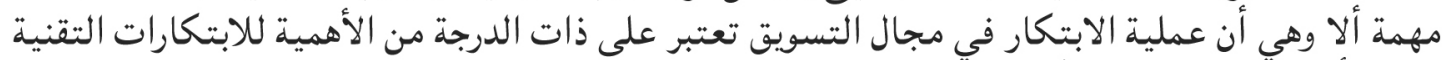

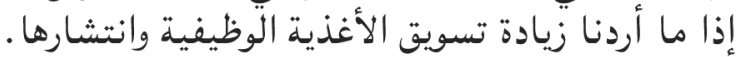

